\title{
Enhancing the Primary Care Team to Provide Redesigned Care: The Roles of Practice Facilitators and Care Managers
}

\author{
Erin Fries Taylor, $P b D^{1}$ \\ Racbel M. Macbta ${ }^{1}$ \\ David S. Meyers, MD \\ Janice Genevro, $\mathrm{PbD}, \mathrm{MSW}^{2}$ \\ Deborab N. Peikes, $P b D^{1}$ \\ ${ }^{1}$ Mathematica Policy Research, Princeton, \\ Washington, DC \\ ${ }^{2}$ Center for Primary Care, Prevention, and \\ Clinical Partnerships, Agency for Health- \\ care Research and Quality, US Department \\ of Health and Human Services, Rockville, \\ Maryland
}

Conflicts of interest: authors report none.

\section{CORRESPONDING AUTHOR}

Erin Fries Taylor, PhD

Mathematica Policy Research 1100 First St NE, 12th Floor

Washington DC 20002

etaylor@mathematica-mpr.com

\begin{abstract}
Efforts to redesign primary care require multiple supports. Two potential members of the primary care team-practice facilitator and care manager-can play important but distinct roles in redesigning and improving care delivery. Facilitators, also known as quality improvement coaches, assist practices with coordinating their quality improvement activities and help build capacity for those activities-reflecting a systems-level approach to improving quality, safety, and implementation of evidence-based practices. Care managers provide direct patient care by coordinating care and helping patients navigate the system, improving access for patients, and communicating across the care team. These complementary roles aim to help primary care practices deliver coordinated, accessible, comprehensive, and patient-centered care.
\end{abstract}

Ann Fam Med 2013;11:80-83. doi:10.1370/afm.1462.

\section{INTRODUCTION}

$\mathrm{R}$ ecently, policy makers have focused on redesigning primary care in the United States with the aim of achieving a 3-part goal of: better patient experience, improved health, and reduced costs. To transform the way they deliver care, practices will require various supports and will need to use teams more effectively. Two potential members of the primary care team, each with unique skills and responsibilities, have been missing from most primary care practices, particularly small- and mediumsized practices, despite having shown promise in improving care. ${ }^{1-3}$

Practice facilitators, also known as practice coaches or quality improvement (QI) coaches, help practices undertake QI projects, understand and use data for QI, and develop capacity for continuous QI. They also often help practices become patient-centered medical homes. Care managersembedded within or otherwise integrated into a practice team-play a direct role in patient care, providing patient education and training in selfmanagement skills and, beyond the walls of the practice, they coordinate care with other clinicians and settings and connecting patients to community resources and social services. Both these team members can play vital roles in the improvement of care delivery, making it more coordinated, comprehensive, and patient-centered. This article discusses the roles of these 2 members of the primary care team and highlights their complementarity in helping practices improve care delivery to better outcomes.

\section{Practice Facilitators}

Practice facilitators work closely with primary care practices to build capacity for QI activities and help the practice reach incremental and transformative improvement goals. ${ }^{4}$ Facilitators work with practice staff to redesign workflows and processes so staff can better serve patients; they do not provide direct care to patients. Facilitators are typically, though 
not always, external to a practice, striking a balance between working closely with practice staff and providing an objective, third-party perspective on practice operations by assisting practices in various ways:

- Helping practices organize, prioritize, and sequence QI activities and, in many cases, achieve medical home recognition

- Training practice staff to understand and use data effectively to drive QI

- Increasing practice capacity for continuous QI activities, and creating and maintaining an ongoing QI infrastructure within the practice

- Building a team orientation and promoting effective communication patterns among practice staff, and helping to create a practice culture that is receptive to change

In contrast to short-term or onetime QI activities, such as academic detailing, facilitation usually involves an ongoing relationship between the facilitator and the practice, although work on specific projects may occur intermittently. Accordingly, facilitators work to develop long-term, trusting relationships with practice staff (including both clinical and administrative staff). Facilitators also play an important role in understanding how all practice staff work together and in helping staff organize the practice's QI efforts. Because facilitators work with multiple practices, they can provide "crosspollination" of best practices and communicate lessons learned across the practice community. In addition, facilitators connect practices to a variety of resources (for example, arranging for a practice to meet with a technical expert relevant to a specific QI topic) and sometimes negotiate with external vendors (for example, firms providing health information technologies). ${ }^{5}$
Given the variety of roles they play, facilitators need a number of skills. Core competencies include excellent interpersonal and communication skills, expertise in acquiring and using data to drive improvement, and knowledge of QI methods. ${ }^{4}$ Facilitators may also need to develop specific competencies for certain QI interventions or activities. Individuals with these skills can come from a variety of backgrounds, and existing programs have hired facilitators from social work, nursing, counseling, health management, and business, among others. Areas in which facilitators have been particularly active recently-reflecting, in part, available funding for facilitation services_-include assisting practices in the meaningful use of electronic health records and helping pursue transformation processes, such as implementing team-based care and patient-centered medical homes. In 2011, the Agency for Healthcare Research and Quality (AHRQ) awarded cooperative agreement grants to 4 state-based coalitions in Oklahoma, North Carolina, New Mexico, and Pennsylvania. These grants support sustainable statelevel initiatives utilizing primary care practice facilitators to assist small- and medium-sized practices with primary care redesign and quality improvement activities. (More information about this initiative is available at http://ahrq.hhs.gov/research/impactaw.htm.)

\section{Care Managers}

The care manager's central role is delivering and coordinating services for patients, including coordinating care across clinicians, settings, and conditions/diseases, and helping patients access and navigate the system. While these care coordination activities may benefit many patients, they can be particularly useful for those

Table 1. Characteristics of Practice Facilitators and Care Managers

\begin{tabular}{|c|c|c|c|}
\hline Role & Core Functions & Connection to Practices and Patients & $\begin{array}{l}\text { Educational } \\
\text { Background }\end{array}$ \\
\hline $\begin{array}{l}\text { Practice } \\
\text { facilitator }\end{array}$ & $\begin{array}{l}\text { Help the practice organize, prioritize, and sequence QI } \\
\text { activities } \\
\text { Train practice staff to understand and use data to drive QI } \\
\text { Increase practice capacity for QI activities } \\
\text { Help build a team orientation among practice staff and a } \\
\text { practice culture receptive to change } \\
\text { Share best practices and lessons across practices }\end{array}$ & $\begin{array}{l}\text { Facilitator is typically employed by an exter- } \\
\text { nal organization (not the practice) } \\
\text { Facilitator works with practice staff (not } \\
\text { patients) } \\
\text { Facilitator typically works mostly on site at } \\
\text { the practice with some interactions by } \\
\text { phone, e-mail, or video conference; some } \\
\text { facilitators work entirely virtually }\end{array}$ & $\begin{array}{l}\text { Social work, } \\
\text { nursing, coun- } \\
\text { seling, health } \\
\text { management, } \\
\text { business, and } \\
\text { other areas }\end{array}$ \\
\hline $\begin{array}{l}\text { Care } \\
\text { manager }\end{array}$ & $\begin{array}{l}\text { Assess the patient's care needs } \\
\text { Develop, reinforce, and monitor individualized care plan } \\
\text { Provide patient education and training in self-manage- } \\
\text { ment skills } \\
\text { Coordinate patient's care with other providers and set- } \\
\text { tings, and communicate needed information } \\
\text { Connect patient to community resources and social services } \\
\text { Participate in practice QI activities }\end{array}$ & $\begin{array}{l}\text { Care manager may be employed by the prac- } \\
\text { tice itself, a payer, or state. They are closely } \\
\text { integrated into the practice team } \\
\text { Care manager provides services to patients } \\
\text { and families } \\
\text { Care manager (as we define) works at the } \\
\text { practice, and may also interact with patients } \\
\text { by telephone, e-mail, in the patient's home, } \\
\text { or in other providers' offices }\end{array}$ & $\begin{array}{l}\text { Nursing, social } \\
\text { work, counsel- } \\
\text { ing, and other } \\
\text { areas }\end{array}$ \\
\hline
\end{tabular}


with chronic conditions and many care needs. ${ }^{6,7}$ Working closely with patients and their families, care managers' activities often include the following:

- Assessing (and regularly reassessing) patients' care needs

- Developing, reinforcing, and monitoring care plans

- Providing education and encouraging selfmanagement

- Communicating information across clinicians and settings

- Connecting patients to community resources and social services

Several of these activities occur between office visits, with care managers working to ensure that patients receive required care and necessary information.

Care managers, as we define them, are practicebased staff with direct patient contact. They take on the coordination activities described above and participate in both the clinical and nonclinical aspects of care. Care managers are sometimes referred to as care coordinators, patient navigators, or patient coaches. (Case managers may also perform the coordination functions described here, although some view case management as more clinical than care management, with an emphasis on a particular disease or condition. Case management can be practice based, but it often is provided by the patient's health plan or managed care organization and involves little to no direct faceto-face patient contact. $)^{8}$ Educational backgrounds of care managers include nursing, social work, and counseling, among others.

\section{Role of Facilitator vs Care Manager: An Example}

Using the example of a disease registry to help a practice track its patients with diabetes, a facilitator and care manager would play different roles. The facilitator might help the practice develop or refine its patient registry, including deciding which types of patient information, laboratory results, and utilization data to collect; what software to use ; and how to populate the registry. The facilitator might teach clinicians, care managers, and other staff how to use the registry to track the practice's panel of patients with diabetes and monitor progress over time in improving diabetes care.

In contrast, the care manager might use the disease registry to actively manage care for individual patients with diabetes. He or she might use this information to monitor and follow up with specific patients, and schedule needed appointments and tests. Thus, the facilitator might use the registry to help the care manager identify patients with diabetes who are not receiving a particular preventive service (such as foot examinations) and discuss why rates for this service are lower than expected and how the practice might boost them. This process could directly inform specific changes in approach, such as how the care manager conducts outreach or how clinicians identify and refer patients with diabetes to the care manager.

\section{Synergies Between Facilitators and Care Managers}

Practices need multiple supports to improve care, and facilitators and care managers play mutually supportive roles in this regard-working at the system and patient levels, respectively. Both expand the primary care team and allow various functions to be performed more cost-effectively by team members other than physicians and nonphysician clinicians. Facilitators and care managers also provide support against the tyranny of the urgent-allowing staff to move beyond patients' acute needs and focus more broadly on providing coordinated, accessible care and improving quality and patient experience. ${ }^{9}$

\section{Funding for Facilitators and Care Managers}

Despite growing consensus about the need for practice facilitators and care managers in primary care teams, establishing and sustaining funding for these positions can be challenging. Currently, facilitation services are often supported by federally funded programs (such as Area Health Education Centers or Health Information Technology for Economic and Clinical Health [HITECH] Regional Extension Centers), state government and/or Medicaid program waivers (for example, the Vermont Blueprint for Health), and philanthropic organizations (such as the Commonwealth Fund's Safety Net Medical Home Initiative and the Robert Wood Johnson Foundation's Improving Performance in Practice program). These funding sources position facilitators as a shared community resource whose services are available to many practices. Health systems that own practices, as well as health plans interested in improving patient-level outcomes, may also fund facilitation. Although uncommon, practices may pay directly for facilitation services.

Care managers are much more likely than facilitators to be paid practice employees. Some payers support practice-based care managers directly by paying their salaries or providing staff; indirect methods of support include paying practices per capita care-management fees or sharing savings or bonuses for achieving certain outcomes. A shared resource approach, in which a care manager works within a practice but serves multiple practices in a community, has also emerged in several areas and may be particularly useful for small or rural practices. ${ }^{10}$ 


\section{CONCLUSIONS}

Primary care practices require multiple supports to transform care and maintain quality improvements over time. Facilitators and care managers are increasingly receiving attention as potentially important players in primary care redesign. They have distinct but complementary roles: facilitators play a vital role in coordinating practice QI and redesign efforts, whereas care managers do the critical work of coordinating patient care. Both aim to deliver coordinated, accessible, comprehensive, and patient-centered care.

To read or post commentaries in response to this article, see it online at http://www.annfammed.org/content/11/1/80.

Key words: care coordination; practice facilitation; primary care; patient-centered care; quality improvement

Submitted April 30, 2012; submitted, revised, July 11, 2012; accepted August 6, 2012.

Disclaimer: The opinions expressed in this document are those of the authors and do not reflect the official position of Agency for Healthcare Research and Quality or the US Department of Health and Human Services.

\section{References}

1. Baskerville NB, Liddy C, Hogg W. Systematic review and metaanalysis of practice facilitation within primary care settings. Ann Fam Med. 2012;10(1):63-74.
2. Brown RS, Peikes D, Peterson G, Schore J, Razafindrakoto CM. Six features of medicare coordinated care demonstration programs that cut hospital admissions of high-risk patients. Health Aff (Millwood). 2012;31(6):1156-1166.

3. McAllister JW, Presler E, Cooley WC. Practice-based care coordination: a medical home essential. Pediatrics. 2007;120(3):e723-e733.

4. Knox L, Taylor EF, Geonnotti K, Machta R, Kim J, Nysenbaum J, Parchman, M. Developing and Running a Primary Care Practice Facilitation Program: A How-to Guide. AHRQ Publication No. 12-0011. Rockville, MD: Agency for Healthcare Research and Quality; 2011.

5. Nutting PA, Crabtree BF, Miller WL, Stewart EE, Stange KC, Jaén CR. Journey to the patient-centered medical home: a qualitative analysis of the experiences of practices in the National Demonstration Project. Ann Fam Med. 2010;8(Suppl 1):S45-S56, S92.

6. Meyers D, Peikes D, Genevro J, Peterson G, Taylor EF, Lake T, Smith K, Grumbach K. The Roles of Patient-Centered Medical Homes and Accountable Care Organizations in Coordinating Patient Care. AHRQ Publication No. 11-M005-EF. Rockville, MD: Agency for Healthcare Research and Quality; 2010.

7. Rich E, Lipson D, Libersky J, Parchman M. Coordinating Care for Adults With Complex Care Needs in the Patient-Centered Medical Home: Challenges and Solutions. White paper. AHRQ Publication No. 12-0010-EF. Rockville, MD: Agency for Healthcare Research and Quality; 2012

8. Antonelli R, McAllister J, Popp J. Making Care Coordination a Critical Aspect of the Pediatric Health System: A Multidisciplinary Framework. The Commonwealth Fund; 2009.

9. Berenson RA, Hammons T, Gans DN, et al. A house is not a home: keeping patients at the center of practice redesign. Health Aff (Millwood). 2008;27(5):1219-1230.

10. Highsmith N, Berenson J. Driving Value in Medicaid Primary Care: The Role of Shared Support Networks for Physician Practices. The Commonwealth Fund; 2011. 